\title{
Research
}

\section{Spanning Boundaries in an Arizona Watershed Partnership: Information Networks as Tools for Entrenchment or Ties for Collaboration?}

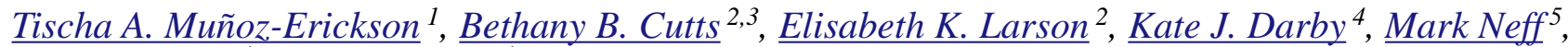 \\ $\underline{\text { Amber Wutich }}^{4}$, and Bob Bolin ${ }^{4}$
}

\begin{abstract}
The need to develop successful collaborative strategies is an enduring problem in sustainable resource management. Our goal is to evaluate the relationship between information networks and conflict in the context of collaborative groundwater management in the rapidly growing central highland region of Arizona. In this region, water-management conflicts have emerged because of stakeholders' differing geographic perspectives and competing scientific claims. Using social network analyses, we explored the extent to which the Verde River Basin Partnership (VRBP), which was charged with developing and sharing scientific information, has contributed to collaboration in the region. To accomplish this, we examined the role that this stakeholder partnership plays in reinforcing or overcoming the geographic, ideological, expert, and power conflicts among its members. Focusing on information sharing, we tested the extent to which several theoretically important elements of successful collaboration were evidenced by data from the VRBP. The structure of information sharing provides insight into ways in which barriers between diverse perspectives might be retained and elucidates weaknesses in the partnership. To characterize information sharing, we examined interaction ties among individuals with different geographic concerns, hierarchical scales of interest, belief systems (about science, the environment, and the role of the partnership), and selfidentified expertise types. Results showed that the partnership's information-sharing network spans most of these boundaries. Based on current theories of collaboration, we would expect the partnership network to be conducive to collaboration. We found that information exchanges are limited by differences in connection patterns across actor expertise and environmental-belief systems. Actors who view scientists as advocates are significantly more likely to occupy boundary-spanning positions, that appear to impede the success of the partnership. This analysis challenges widely held assumptions about the properties that separate successful collaborations from those that are less successful. It has implications for our understanding of the factors that constrain information processing, knowledge production, and collectiveaction capability in institutions.
\end{abstract}

Key Words: Arizona; boundary spanning; collaborative management; environmental governance; information networks; power; water management

\section{INTRODUCTION}

Watershed partnerships are increasingly common in natural resource management. Also known as councils, committees, and advisory groups, these partnerships offer an organizational forum in which multiple policy stakeholders, including environmental groups, local landowners, government agencies, and concerned citizens, can come together to discuss and negotiate watershed management plans
(Cortner and Moote 1999, Leach and Pelkey 2001). Collaboration is a flexible policy tool for addressing environmental impacts in a cost-effective manner (Lubell et al. 2002). At their best, partnerships provide inclusive and creative ways to reach consensus on acceptable policies, and develop the information, trust, and social capital necessary to foster mutual learning (Galaskiewicz 1985, Cortner and Moote 1999, Pahl-Wostl et al. 2007). Often, improved communication and information exchange

\footnotetext{
${ }^{1}$ School of Sustainability, Arizona State University, ${ }^{2}$ School of Life Sciences, Arizona State University, ${ }^{3}$ Decision Center for a Desert City, Arizona State University, ${ }^{4}$ School of Human Evolution and Social Change, Arizona State University, ${ }^{5}$ Consortium for Science, Policy and Outcomes, Arizona State University
} 
lead to better environmental and political literacy for all parties (Ostrom 1990, Hardy et al. 2003) and can potentially foster adaptive capacity across the various levels of governance involved (Olsson et al. 2004, Armitage 2005). By including a wide range of participants, collaborative decisions are able to draw from wider resources, reduce decision making uncertainty, enhance decision legitimacy, and more effectively attain collective goals (Galaskiewicz 1985, Ostrom 1990, Prell et al. 2008).

Yet, despite the growing literature documenting the benefits and successes of watershed partnerships and collaborative management in general (Wondolleck and Yaffee 2000, Sabatier et al. 2005) success is far from guaranteed. In central Arizona, for example, the Verde River Basin Partnership (VRBP) was created by federal legislation in 2005 to develop and share scientific information to inform watershed management in the Central Highlands region with the intent of alleviating controversy over water management in the region (Northern Arizona Land Exchange and Verde River Basin Partnership Act 2005). Despite Congress's intent and the VRBP's collaborative mandate, the group continues to face numerous obstacles because of conflicts between upstream and downstream interests groups over groundwater withdrawals (Bolin et al. 2008).

The southwestern United States is an arid region with a rapidly growing population, and water politics has long been central to local and regional politics (Worster 1985, Reisner 1993, Hirt et al 2008). The Colorado River, which drains parts of seven U.S. states and two Mexican ones, is the main source of surface water for much of the region. Groundwater use has complemented surface water resources to accommodate population growth and widespread agriculture. However, heavy reliance on groundwater is unsustainable in the region, because of incredibly long recharge times and local problems with ground-level subsidence (Jenkins 2006). In 1980, Arizona enacted the Groundwater Management Act (GMA) with the intent of ending unsustainable groundwater withdrawal by 2025 by placing restrictions on groundwater use in the most populous and rapidly growing parts of the state, areas termed "Active Management Areas" (Fig. 1) by the law. Passing the law secured California's support in Congress for the Central Arizona Project (CAP), a canal to bring Colorado River water to the population centers of Arizona (Reisner 1993, Hirt et al 2008).
The site of our case study, the Prescott Active Management Area (PrAMA), is one of five currently designated Active Management Areas in Arizona. For the Phoenix AMA, the CAP canal and other local rivers (Salt and Verde) make the goal of ending net groundwater withdrawal by 2025 comparatively attainable. However, the PrAMA does not have substantial surface water, nor does it currently have a means for Colorado River water delivery. The region also continues to face rapid growth, with an estimated $3 \%$ population increase per year (Collins and Bolin 2007).

Because of its lack of other water sources, the PrAMA received the only exception in the GMA that allows it to import groundwater from outside the AMA. This exemption created a host of transboundary issues and placed significant importance on the legal distinction between groundwater and surface water. These two forms of water, although legally distinct, may or not be physically linked, and controversies abound over the impact of groundwater withdrawal on surface waters of the Verde River and the downstream biological and human communities that depend on it outside of the PrAMA. Downstream communities, including civil-society groups, municipal, federal, state, and county government agencies (Fig. 2) have disputed the plans to transfer groundwater and, in some cases, threatened with legal action based on scientific evidence that the transferring groundwater will negatively affect surface water. Those in favor of the groundwater transfer similarly mobilize scientific evidence to support their claims. As depicted in Fig. 2, the VRBP was developed as a forum for communication across interests with the intention of identifying questions for which additional scientific information on the hydrological and ecological impacts of the water transfer might help generate mutually agreeable management options (Northern Arizona Land Exchange and Verde River Basin Partnership Act 2005). Nonetheless, conflict persists, and after the initial meetings of the VRBP, several of the upstream municipal and county representatives left the group because they perceived inequities in the voting structure.

Several factors could explain why conflict persists in watershed partnerships such as the VRBP. The policy and organizational literature posits that collaboration may be inhibited by deeply entrenched political interests that are not amenable to resolution, by lack of trust, by lack of alternative 
Fig. 1. Map of the case study.

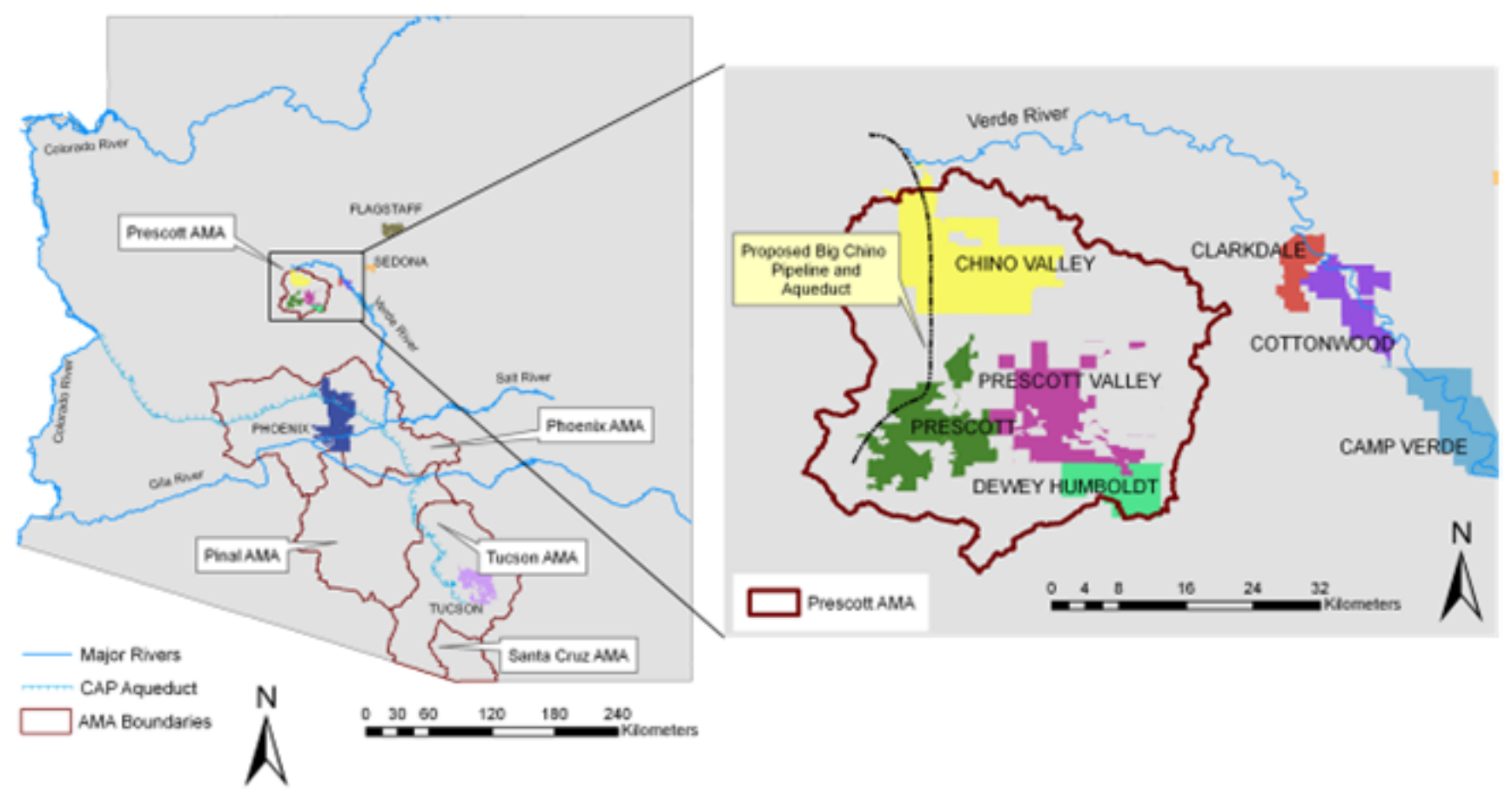

Note: Red boundaries indicate Arizona active management areas (AMAs). The picture to the right shows the Prescott Active Management Area (PrAMA) within the red boundary, the proposed Big Chino Pipeline and Aqueduct, and the downstream communities along the Verde River.

management options, and by a constricting external institutional structure (Leach and Pelkey 2001, Manring 2007). Recent analysis carried out on political conflict in the central Arizona region reveal that, rather than reaching consensus, stakeholders mobilize scalar arguments (Bolin et al. 2008) and use competing scientific claims to bolster their ideological and policy preferences. Specifically, a dispute over scientific information connecting groundwater to surface water is seen by some as the central issue fueling political conflict (O'Halleran, personal communication). Although information sharing is considered a critical resource for increasing a partnership's learning capacities (Manring 2007), little attention has been paid to how the use and sharing of information, that is, the flow of information through a partnership's network, affects how collaboration works and whether it succeeds in minimizing resource management conflict.
We seek to evaluate the relationship between information networks and conflict in the context of collaborative groundwater management and the VRBP in central Arizona. Specifically, we use the tools of social network analysis to explore how the VRBP's information network facilitates or limits stakeholders' capacity to bridge the ideological and geographical boundaries that permeate this partnership.

Social network theory suggests numerous ways that network structure or, more specifically, the relationships or ties among network units called nodes or actors (e.g., people, websites, organizations) can influence organizational outcomes (e.g., Provan and Milward 1995). Recently, network analysis has been used to evaluate power distribution and cooperation in regional and water-related partnerships across multiple policy levels (Henry 2007, Berardo 2009). 
Fig. 2. Conceptual model depicting the diverse set of political groups with interests in the Verde region and the Big Chino Water Project.

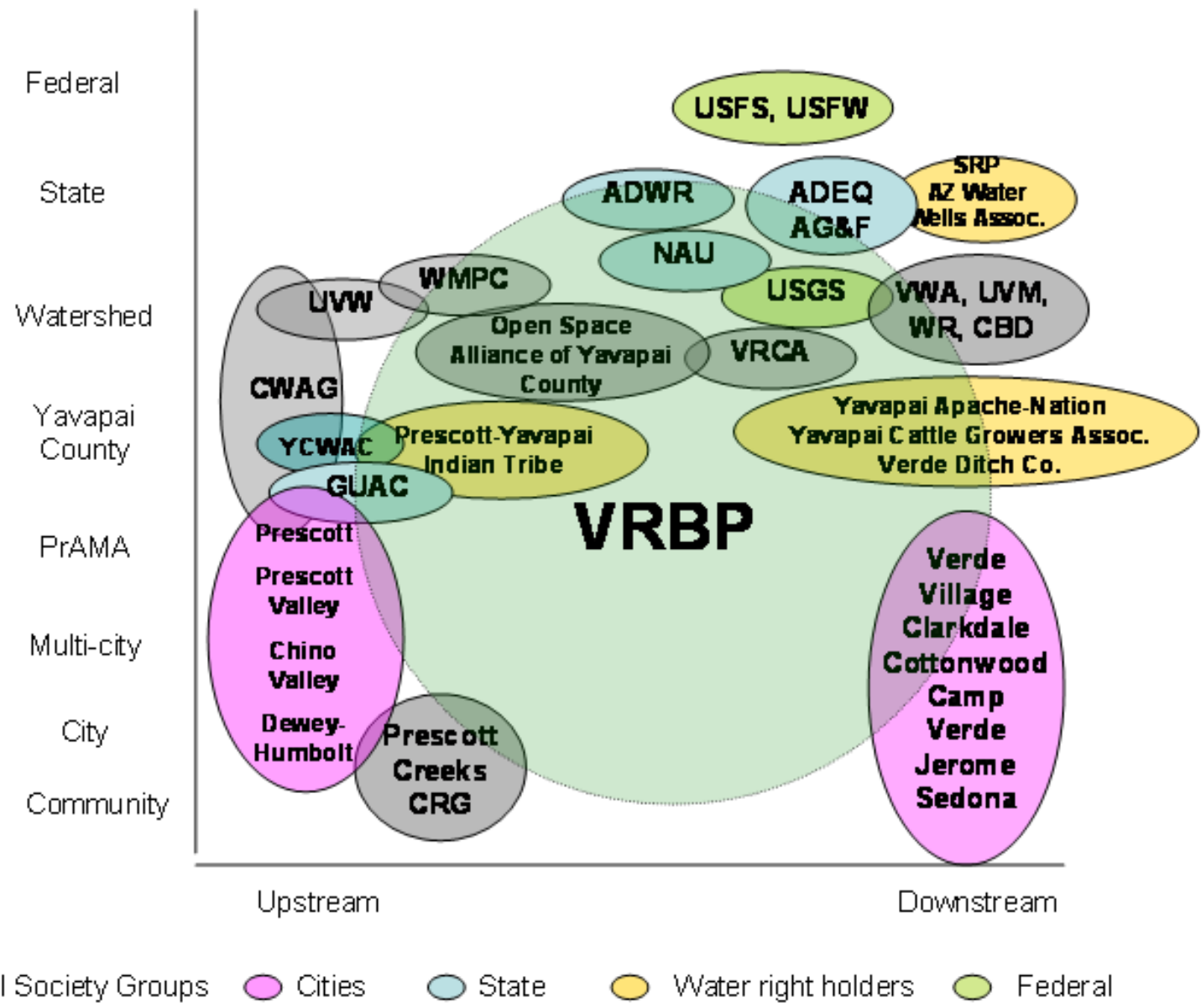

Note: The axes represent where each group and alliances align themselves in respect to their vertical and horizontal interests.

For instance, Schneider et al. (2003) demonstrate that successful partnerships, in comparison to noncollaborative management approaches, are able to span multiple geographic, ideological, and expertise boundaries and, therefore, be more effective at collective decision making.

We propose that applying network analysis to understand how a partnership's information network influences its ability to span multiple internal boundaries and power differences provides insight into the functioning of collaborative organizations and the role of information sharing as a source of conflict, insights that are not evident through other methodologies. In conducting this research, we address recent calls in this journal to apply a network perspective to understand structural effects on collaborative approaches to natural resource management (Bodin et al. 2007). 


\section{Boundary Spanning and Power in Collaborative Information Networks}

Understanding the structural relationships of partnerships through social network analysis can help determine the role that information exchange networks may play in promoting, and/or inhibiting collaboration (Hardy et al. 2003). For example, it can help identify if asymmetries of information flow and use of science exist, and if these asymmetries create barriers to collaboration. As Tilt et al. (2008) found in a survey of 125 collaborative groups in the western U.S., ideological conflicts are often surmountable barriers to progress, but conflict over issues of fact or information can incapacitate the process. These conflicts may occur by marginalizing nonscientist participants (Koontz et al. 2004) or by privileging "expert" knowledge over other types of knowledge (Brunner et al. 2005).

Complementary to the collaborative management literature, social network theory suggests that tight network connections within a perspective, but not across perspectives, often indicate a source of conflict. Dense ties within a perspective suggest homophily, or the tendency of people to affiliate with those who have similar ideas. When there is evidence that a particular perspective or characteristic of the respondents corresponds with tie frequency, then we might surmise that homophily plays a prominent role in conflict (e.g., Shutters and Cutts 2008). Similarly, social network methods can illuminate power differences through measures of centrality that relate to how many ties an individual has (in the case of degree centrality) and how many unique groups are only connected through that individual ("betweenness centrality"). In other words, social network structure can either benefit or obstruct the goals of collaboration. Network connections can allow access to diverse and dispersed knowledge (Wegner 1987, Moreland et al 1996, Rulke and Galaskiewiscz 2000) and decrease levels of internal conflict. On the other hand, this often leads to a homogenous belief system (Krackhardt and Stern 1988, Ibarra 1992, Reagans and Zuckerman 2001). When these homogenous beliefs foster polarized "us versus them" mentalities between groups of actors within a partnership, conflict can become deeply entrenched (Krackhardt and Stern 1988). If homophily is structuring relationships, we would expect to see more withingroup ties than between-group ties within the VRBP (Fig. 3). If access to diverse and dispersed knowledges is a priority of groups within the network, then the network might exhibit higher frequencies of between-group ties in statistical pairwise comparisons.

Social network analysis is an appropriate tool to evaluate water-related partnerships, especially because natural components of hydrological systems rarely restrict themselves to governance at a single scale. Previous authors have applied a social-network approach to examine the nature of ties across vertical, horizontal, expertise, and ideological boundaries, arguing that spanning these boundaries make partnerships more effective at collaborative management (Schneider et al. 2003). These authors relate vertical position to levels of government, horizontal position to geographic jurisdiction, expertise position to scientific training and ideological position to views underlying issue positions. Following their approach, we hypothesize that conflict persists because information-sharing links within the network do not span vertical, horizontal, expertise, and/or ideological boundaries.

\section{Boundary spanning hypotheses}

Hypothesis $1 a(\mathrm{H} 1 a)$

Conflict persists because of vertical stratification: When different levels of political concern are linked, partnerships are able to advance perspectives that consider political priorities at those multiple scales from national to local and initiate action at the levels that are most appropriate and effective (Schneider et al. 2003, Collins and Bolin 2007). If vertical stratification perpetuates conflict, than we would expect that network ties will be denser within a vertical layer than across vertical layers.

\section{Hypothesis $1 b(\mathrm{H} 1 b)$}

Conflict persists because of horizontal stratification: Successful partnerships are able to bridge boundaries between horizontally stratified interests. The VRBP was initially intended to straddle upstream and downstream interests. Many of the upstream interests are no longer part of the partnership, so our ability to examine the horizontal span of the network is constrained. If horizontal stratification perpetuates conflict, then we would expect that network ties will be denser within horizontal boundaries than across horizontal boundaries. 
Fig. 3. Simplified examples of social networks.

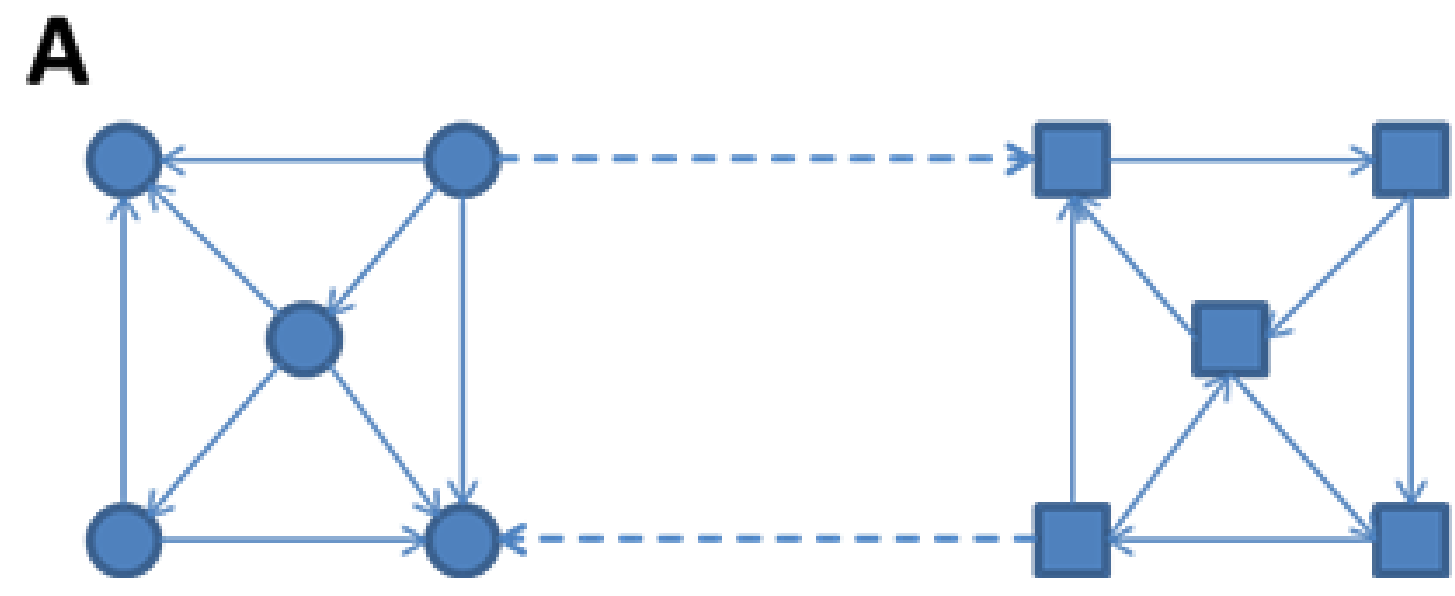

B

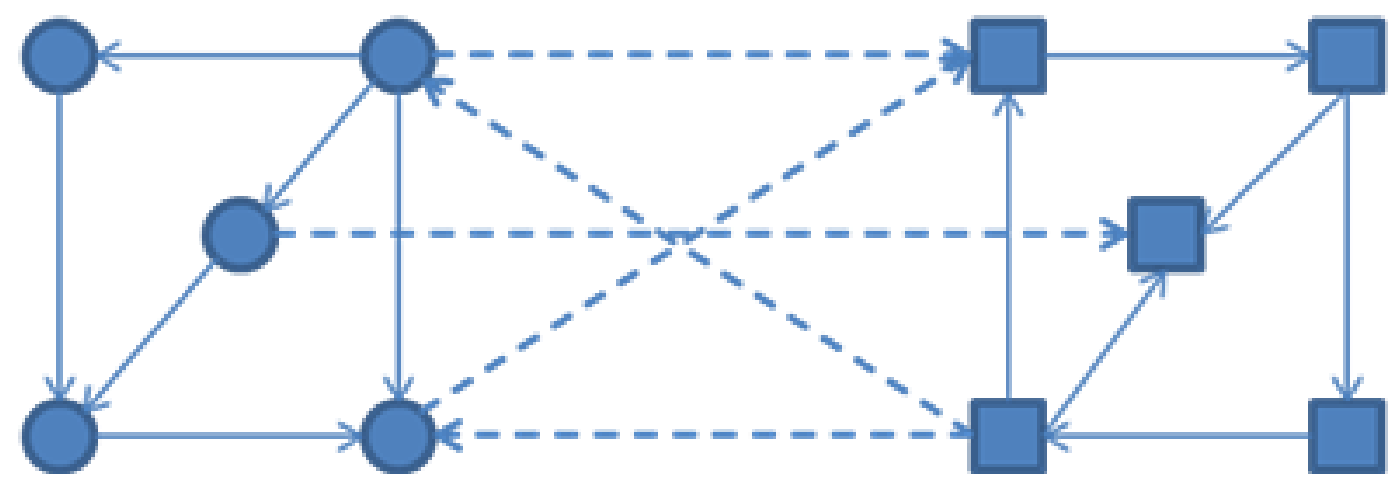

Note: Actors are represented by shapes and ties as the arrows between them. The type of shape (circle or square) separates the actors into groups based on the attributes of interest (e.g., expertise or ideology). In (A), groups exhibit strong homophily, with more within-group ties than between-group ties. In (B), within-group ties do not significantly outnumber between-group ties, resulting in more opportunities for interaction among groups.

Hypothesis $1 c(\mathrm{H} 1 c)$

Conflict persists because of ideological differences: Social network theory suggests that tight cliques of individuals or organizations with similar perspectives to one another, but very different perspectives across groups might indicate a primary source of conflict. We operationalize this by examining: (1) environmental values, measured via the New Environmental Paradigm (Dunlap et al. 2000), (2) differing perceptions about where the biggest barriers to decision making occur in this particular context (Marshall et al. 2007), (3) differing views on the objectivity of science (positivism; as discussed in Steel et al. 2004), (4) differing views on the role of scientists as activists (Steel et al.2004), and (5) political ideology. If ideology along these axes conserves conflict, then we would expect that network ties will be denser within an ideology than across ideologies. 
Hypothesis $1 d(\mathrm{H} 1 d)$

Conflict persists because of inadequate communication between experts and non-experts: Actors in decision making in the United States frequently cite technical reasons for their preferred policy outcomes (Jasanoff 1990). News reports and previous interviews confirm that the controversy in this case is similarly argued in technical terms (Bolin et al. 2008, O'Halleran, personal communication). Thus, we can hypothesize that the controversy remains intractable because of inadequate connections between those who have access to, and understanding of, the technical aspects of this debate. If expertise boundaries perpetuate conflict, then we would expect that network ties will be denser within an expertise type than across expertise types.

\section{Power hypotheses}

Power asymmetries in networks often promote conflict (Brass et al. 2004), whereas collaboration most frequently persists when power is equally distributed (Ostrom 1990). From previous research, we know that citizen-activist groups in the central Arizona highlands have appealed to larger geographic and political scales in attempts to increase their power (Bolin et al. 2008). We do not know how effective this has been at moving them to a greater position of power within the VRBP. Given the constraints of the study, we cannot test this directly though empirical methods. However, we can use a combination of descriptive statistics and hypothesis testing methods to investigate how differences in power are distributed and conjecture about implications this might have for the network.

Although it is not the only source of power, network position can determine the amount of influence individuals have over information dispersal (Ibarra 1993). Central actors may determine the type of knowledge that is generated in the network as their beliefs and prior knowledge influence how useful, relevant, and reliable is the information they have access to (Davy 2006, Choo Wei 2007). We expect that the extent of power differentials in how information is accessed and used in the network will influence cooperation. Network characteristics can be used to identify people in positions of power (Brass and Burkhardt 1993, Ibarra 1993, Brass et al. 2004).
Hypothesis $2 a(\mathrm{H} 2 a)$

In-degree centrality will not vary significantly with vertical, horizontal, expertise, or ideological position: Measures of in-degree centrality and betweenness centrality are most relevant to our research. In-degree centrality, measured by connections from others to a node, indicates prestige (Knoke and Burt 1983, Brass and Burkhardt 1993), and is robust to response rates lower than $100 \%$ (Costenbader and Valente 2003). These individuals are objects, and not necessarily sources, of communication (Knoke and Burt 1983). Correspondence between traits of actors (in $\mathrm{H} 1 a-d$ ) and in-degree centrality indicates perceptions of power by other members of the network. If we find, for example, that that actors who think that scientists should not act as decision makers hold central positions, then conflict might be more likely to persist.

\section{Hypothesis $2 b(\mathrm{H} 2 b)$}

Betweenness centrality will not vary significantly with vertical, horizontal, expertise, or ideological position: Betweenness centrality, also sometimes called brokerage (e.g., Bodin et al. 2005), is also relevant to our concerns. Betweenness-centrality calculations are based on the number of times an actor falls on the "shortest pathway" between two other actors and has been used to measure control over resources and indicates power over information gatekeeping (Brass and Burkhardt 1993). Correspondence between traits of actors (in Hypotheses $1 a-d)$ and betweenness centrality indicates information bridges in network. If the results indicate a particular trait is associated with higher betweenness centrality, then they may be limiting the potential for consensus by restricting information flow. If they support a perspective that is not popular, they exaggerate the extent to which it has permeated groups for whom there are few other regular sources of information.

Either high in-degree or high betweenness centrality means that the actor can act as an information gatekeeper, facilitating information transfer he or she views as helpful, and preventing information he or she views as counterproductive from being widely dispersed to their contacts. In networks with distributed power, this is less problematic, as there are alternative pathways to allow for information transfer (Bodin et al. 2006). The relative evenness 
of power distribution within a network can be assessed by calculating network centralization (Hanneman and Riddle 2005).

\section{Case Study: Big Chino Water Conflict and the Verde River Basin Partnership}

The lack of surface water, coupled with population growth in the region, has pushed PrAMA's search for water outside of the AMA boundaries. The most visible current proposal, the Big Chino Project (BCP), a pipeline that would pump groundwater from the Big Chino aquifer, $48 \mathrm{~km}$ (30 miles) north of the PrAMA (Barks 2007). Residents outside of municipal water systems rely on 27,000 "exempt" wells that are not regulated under the GMA. The PrAMA still primarily relies on water from the Little Chino aquifer, which some believe will be depleted in 130 yrs (Collins and Bolin 2007). Controversies over scientific information specifically revolve around whether the Big Chino and Little Chino aquifers, the source of water for the BCP and PRAMA, are connected to the headwaters of the Verde River, thus potentially affecting surface flows of the river and the wildlife and downstream users dependent on it. Several reports, including two issued by the United States Geological Survey, suggest that pumping the Big Chino aquifer will draw down the Verde River (Wirt et al. 2004, Langenheim et al. 2005). However, other reports have pointed out that uncertainties exist over whether changes in groundwater levels because of historic or current pumping in the shallow aquifers (McGavock 2003). These reports have become tools in the political struggle, pitting the different interests against each other, specifically those representing upstream and downstream interests (Bolin et al. 2008).

The Verde River Basin Partnership (http://www.ve rderiverbasinpartnership.org/) was created by federal mandate through Title II of Public Law $109-110$, in which it is "...collaborative and sciencebased water resource planning and management partnership for the Verde River Basin in the State of Arizona, consisting of members that represent (1) federal, state, and local agencies; and (2) economic, environmental, and community water interests in the Verde River Basin." The group is tasked with an action item: identify "long-term water supply management options for communities and water resources within the Verde River Basin and [complete] water resource analyses and monitoring needed to support the implementation of management options." Specifically, the partnership is required to submit a final report to the United States Department of Agriculture and Governor of Arizona that includes a summary of the results of water resource assessments, as well as identification of areas in the Verde River Basin that are determined to have groundwater deficits or other current or potential water supply problems, long-term water supply management options, and resource analysis and monitoring needed to support the implementation of management strategies.

Although the partnership's goals are to gather and generate science-based information, and not to decide on specific management strategies, some of the upstream interests, specifically the major cities within the PrAMA, have contested the role of the partnership in the larger institutional context (McNulty 2008, personal observation). Because the partnership allowed participation by civil-society groups, whose representatives are not part of formal democratic processes, several of the PrAMA community members withdrew from the partnership and formed the Upper Verde Watershed Protection Coalition. In response, the partnership and its major state supporters, including Senator John McCain, have tried to convince the PrAMA members that it is in their benefit to join the VRBP and have cited the success of the Upper San Pedro Partnership (USPP) in southern Arizona as a successful collaboration model for VRBP. The USSP was formed to address concerns about the sustainability of the San Pedro River region in southern Arizona, and generate collaboration among multiple stakeholders to produce knowledge on the relative impacts of water uses on stream flow and to design strategies for conserving water. This research has been successful in helping assess the water budget for the rivers by local municipal, industrial, and agricultural users and generating management strategies for implementation (Browning-Aiken et al 2004). The extent to which the VRBP can be modeled according to the USPP is questionable, given that in the latter there is an agreed-upon goal within the partnership and most debates over scientific information have been resolved, conditions that do not hold similarly in our case study.

In light of these disagreements, we analyze the function of the VRBP as an information and sciencecoordinating body, as opposed to a policyproducing body. The short duration of the VRBP (2 
yrs) lends itself to an analysis of the role that this information network plays as a crucial precondition for building co-operative institutions, and as a baseline for examining its effects on policy formation in the future.

\section{METHODS}

\section{Data Collection}

Our survey instrument includes a social network component, an affiliation and identity component, and a worldview component (See Appendix 1). It draws from a diverse arrangement of previously validated survey questions that use and "strongly agree" to "strongly disagree" scales to represent complicated underlying constructs. These include summative scales developed to assess ascription to the New Environmental Paradigm (Dunlap et al. 2000), views of science and the role of scientists in policy formation (Steel et al. 2004), and perceptions of dominant barriers to achieving the VRBP's objectives (Marshall et al. 2007). It also includes a single item to assess political ideology (General Social Survey 2006). The political ideology (Liberal to Conservative) question is a highly reliable and valid measure, taken from the General Social Survey administered throughout the United States. Conservative ideology generally emphasizes empowerment of the individual, whereas Liberal ideology generally emphasizes the responsibility of government. We used organizational affiliation, job title, and identity questions to determine vertical, horizontal, and expertise characteristics for each individual in the sample frame.

\section{Sampling Procedure}

Because the sampling frame used in whole network studies can have tremendous consequences for the outcomes (Wasserman and Faust 1994, Provan et al. 2007), we used the list of attendees from the first VRBP meeting, inviting all 42 members from the list to participate. To determine the sufficiency of this sampling frame at capturing the dominant interactions regarding the VRBP, we allowed respondents to free-list others with whom they routinely shared Big Chino-related information. Following Dillman's Tailored Design Method (2000), we implemented a multimodal (paper and internet) survey design, contacting potential respondents multiple times. Approximately three times over six weeks, we provided email and/or telephone reminders to nonrespondents. After six weeks, we sent a hard copy of the survey to remaining nonrespondents.

\section{Analysis}

We used SPSS v.15.0 (2001) to calculate descriptive statistics using survey responses and to test the validity of item scales using principle component analysis. Because our sample size was small, none of the item scales (New Environmental Paradigm, views of science, role of scientists as role of scientists in policy formation, and perceptions of dominant barriers to achieving the VRBPs objectives) resulted in a single factor. As an alternative, we used responses to construct binary categories for each of these world view components as well as the political ideology question.

We used the "frequent interaction" graph for social network analysis of information sharing. This graph represents ties between individuals who interact with one another at least weekly. From this graph, we calculated centrality measures for each actor using UCINET (Borgatti et al. 2002). We calculated in-degree centrality and betweenness centrality to use as measure of power (Brass and Burkhardt 1993) and information brokerage (Chan and Liebowitz 2006), respectively. We did not assume that all reported ties were reciprocated because we were interested in capturing differences between in perception of links (Krackhardt 1987, Ibarra 1993). We used survey responses and the network in tandem to test our hypotheses using three network hypothesis-testing methods.

Actor connections to those with similar knowledge and/or attitudes can be quantified in a variety of ways. Least stringently, joint-count contingency tables can be used to determine whether or not there is a significant difference in number of ties among groups. More conservatively, structural-block UCINET ANOVA models can be used to identify difference in ties between and across perspectives. Using relational-contingency analysis, we tested whether or not there was a difference in the number of ties within perspectives versus across perspectives. This test is a global test for difference in tie distribution (Hanneman and Riddle 2005). Next, we used more specific tests of homophily for each perspective outlined in hypotheses $\mathrm{H} 1 \mathrm{a}$ to $\mathrm{H} 1 d$. We also used a structural-block model to look for 
more specific patterns of difference between withinperspective and among-perspectives ties. This is an ANOVA density model. It tests for differences in the pattern of within-perspective and amongperspectives ties by each characteristic. It does not specify a direction of difference. The statistical test can tell us if some groups are more likely to reach out to other groups or if others are more likely to be insular.

To determine whether or not particular network positions affiliated with power were more likely to be filled by actors with particular characteristics, we used the UCINET ANOVA test. UCINET's hypothesis-testing algorithms include bootstrap routines to overcome the problem of sample nonindependence (Hanneman and Riddle 2005).

The social network information for our work has been collected using a survey methodology that relies on recognition, that is, selecting names provided, rather than recall. Because of this, there are two major limitations: (1) some nodes may overreport their ties, and (2) not all ties reported are reciprocal. Accommodating these limitations in interpretations is fairly straightforward. By focusing on in-degree centrality as an indicator of power, we can limit the effect of an individual's tendency to over-report tie strength. It also makes it possible to capture at least some of the power of the nonrespondents. The study is one of people's perspectives on their interrelation, which is often as influential, if not more influential, than their actual interrelations (Marsden 1990, Gunther and Story 2003).

\section{RESULTS}

Thirty one out of 42 (73.8\%) of potential survey respondents completed the Big Chino Project Survey between November 2007 and January 2008. Participants reported being involved with issues pertinent to the proposed Big Chino Water Ranch for between 2 and 28 yrs with an average of 7.8 (standard deviation: 5.5). Metrics for the whole network indicate a density of 0.056 , and in-degree network centralization of 0.19 (Fig. 4).

Within the whole network, diverse vertical, horizontal, expertise, and ideological perspectives are represented (Table 1). Six vertical levels are represented, with watershed-level interests being most commonly represented. Horizontally, downstream interests are represented twice as frequently as upstream interests. More respondents report environmental values that align with the "dominant social paradigm" than a more pro-environmental perspective. Values and information are most commonly cited as the dominant barrier to decision making. Respondents tend toward strongly positivistic views of science, generally think that scientists should play a dominant role in policy formation, and also tend to view themselves as more Liberal than Conservative. There are slightly fewer respondents with self-reported scientific expertise than with nonscientific (Table 1).

Hypothesis 1:

Conflict persists because information sharing links within the network do not span vertical, horizontal, expertise, and/or ideological boundaries.

Using both joint-count contingency analysis and a structural-block model (ANOVA), there are no significant differences between within-group and across-group network ties because of $\mathrm{H} 1 a$ vertical stratification or $\mathrm{H} 1 b$ horizontal stratification (Table 2 ). However, there are some significant differences in the frequency of within- and between-group ties related to $\mathrm{H} 1 c$ ideological differences. Although there are no significant differences in the joint-count contingency analysis and a structural-block model (ANOVA) by: (1) environmental values or perspectives on (2) barriers to decision making, pairwise comparisons of (3) science as positivism, (4) scientists as advocates for policy, and (5) political view were significant (Table 2 ). These include significantly higher rates of information sharing from ecocentrists to the dominant social paradigm (Table 3) and from those with Conservative political views to more Liberal respondents (Table 3). When examining H1d expertise, the frequency of scientists acknowledging information sharing with nonscientists is lower than expected by chance (Table 3 ).

Hypothesis 2:

Conflict persists because power in the network is unevenly distributed across vertical, horizontal, expertise, and/or ideological barriers.

Betweenness ( $\mathrm{H} 2 a)$ and degree $(\mathrm{H} 2 b)$ centrality are significantly different for those who think of scientists as policy advocates and those who do not (betweenness centrality F: 1.647 df: 19, p: 0.044; degree centrality F: 2.767 df: 14, p: 0.005). 
Fig. 4. Map of network connections indicated by respondents.

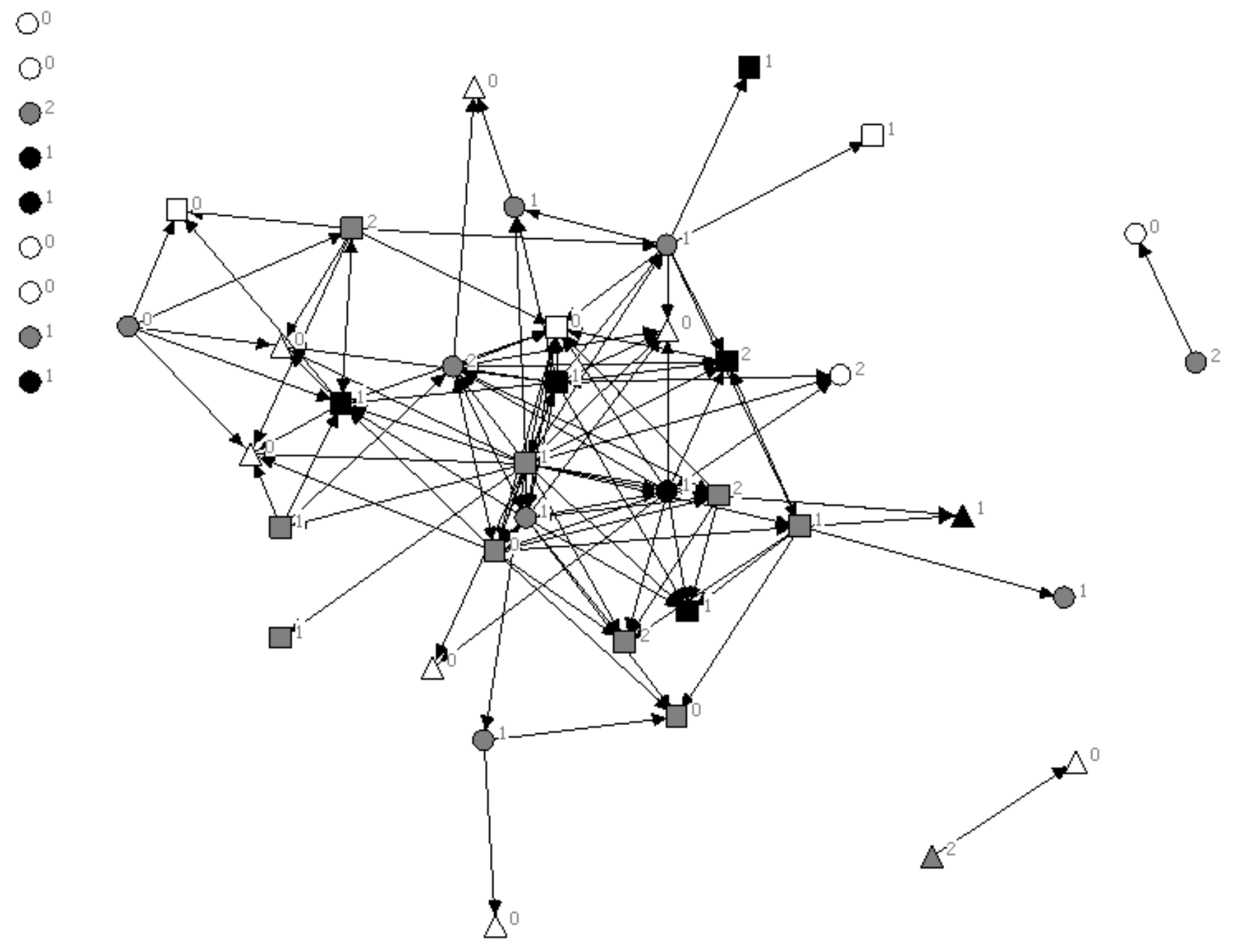

Note: Ties represent reported information sharing "at least monthly." Node shape represents expertise types (triangle $=$ unable to identify, square $=$ nonscientist, circle $=$ scientist). Node shade represents environmental values (no fill $=$ nonrespondent, gray $=$ pro-environmental, black $=$ business as usual). Node label indicates political views $(0=$ nonrespondent, $1=$ Liberal, $2=$ Conservative $)$.

\section{Discussion of Results and Directions for Future Research}

In many ways, the VRBP social network structure does not interfere with the general-process goals outlined in the academic literature for successful ecosystem and water resource management by facilitating information flow (Schneider et al. 2003,
Bulkeley 2005, Lebel 2005, Cash et al. 2006). Although the low density of ties across the whole network indicates that there is space for conflict to persist, tests for homophily indicate that members of the VRBP interact across most of the perspectives outlined in our hypotheses. No strong cliques emerge to reinforce communication within one perspective at the expense of communication across 
Table 1. Frequency of independent variables for Hypotheses $\mathrm{H} 1 a-\mathrm{H} 1 d$.

\begin{tabular}{|c|c|c|}
\hline & Frequency & Percent \\
\hline \multicolumn{3}{|l|}{ H1a: vertical } \\
\hline cities & 6 & 14.29 \\
\hline county & 5 & 11.90 \\
\hline watershed & 9 & 21.43 \\
\hline state & 2 & 4.76 \\
\hline nation & 7 & 16.67 \\
\hline tribal & 1 & 2.38 \\
\hline unknown & 2 & 4.76 \\
\hline missing & 10 & 23.81 \\
\hline \multicolumn{3}{|l|}{ H1 $b$ : horizontal } \\
\hline downstream & 20 & 47.62 \\
\hline upstream & 10 & 23.81 \\
\hline tribal & 1 & 2.38 \\
\hline unsure & 3 & 7.14 \\
\hline missing & 8 & 19.05 \\
\hline \multicolumn{3}{|l|}{ H1c (i): environmental values } \\
\hline pro-environmental & 20 & 47.62 \\
\hline dominant social paradigm & 9 & 21.43 \\
\hline missing & 13 & 30.95 \\
\hline \multicolumn{3}{|l|}{ H1c (ii): science attitudes } \\
\hline weakly positivist & 6 & 14.29 \\
\hline strongly positivist & 23 & 54.76 \\
\hline missing & 13 & 30.95 \\
\hline \multicolumn{3}{|l|}{ H1c (iii): scientist attitudes } \\
\hline nonadvocate & 13 & 30.95 \\
\hline advocate & 17 & 40.48 \\
\hline missing & 12 & 28.57 \\
\hline
\end{tabular}




\begin{tabular}{|c|c|c|}
\hline \multicolumn{3}{|c|}{ H1c (iv): political ideology } \\
\hline Liberal & 19 & 45.24 \\
\hline Conservative & 7 & 16.67 \\
\hline missing & 16 & 38.10 \\
\hline \multicolumn{3}{|l|}{$\mathrm{H} 1 c(\mathrm{v})$ : barriers } \\
\hline trust & 2 & 4.76 \\
\hline resolution process & 3 & 7.14 \\
\hline management & 1 & 2.38 \\
\hline legislation & 5 & 11.90 \\
\hline information & 7 & 16.67 \\
\hline values & 11 & 26.19 \\
\hline missing & 13 & 30.95 \\
\hline \multicolumn{3}{|l|}{ H1d: expertise } \\
\hline nonscientist & 17 & 40.48 \\
\hline scientist & 11 & 26.19 \\
\hline missing & 14 & 33.33 \\
\hline \multicolumn{3}{|c|}{$\begin{array}{l}\text { Note: Schneider et al. (2003) relate vertical position to levels of government, } \\
\text { horizontal position to geographic jurisdiction, expertise position to scientific } \\
\text { training, and ideological position to views underlying issue positions. Vertical, } \\
\text { horizontal, and expertise codes were coded by researchers using definitions derived } \\
\text { from these criteria. The worldview component draws from previously validated } \\
\text { survey questions. These include scales developed to assess } 3 a \text { ) environmental } \\
\text { values (Dunlap et al. 2000), } 3 b \text { ) science attitudes, } 3 c \text { ) the role of scientists in policy } \\
\text { formation (Steel et al. 2004), } 3 d \text { ) political ideology (General Social Survey 2006), } \\
\text { and } 3 e \text { ) perceptions of dominant barriers to achieving the VRBP's objectives } \\
\text { (Marshall et al. 2007). }\end{array}$} \\
\hline
\end{tabular}

perspectives, a characteristic more common in networks with dense connections and/or homogenous perspectives (Rowley 1997). However, there are observable patterns in the effort individuals exert to communicate across perspectives and the likelihood of some perspectives to occupy central positions in the network. Differences in ties between those with pro-environmental views and others ascribing to the dominant social paradigm indicate that proenvironmental members are spending more effort interacting with those of the dominant social paradigm than with other pro-environmental members. This might be explained by a perception that the dominant social paradigm view has more information to share and/or influence in outside decision-making bodies or that the proenvironmental groups perceive their perspective as underacknowledged and therefore feel a need to actively spread information. In terms of political ideologies, this relationship is driven primarily by the frequency with which Conservatives tie to Liberals, which is probably partially driven by the 
Table 2. Tests for respondent attribute affilliation with tie frequency across and within horizonal and vertical scope, worldview characteristic (environmental values, science attitudes, scientist attitudes, political ideology, and barriers to decision making), and expertise type.

\begin{tabular}{lcccc}
\hline \hline & Joint-count contingency analysis & $\begin{array}{l}\text { Structural-block } \\
\text { model }\end{array}$ & \\
\hline & Chi-square & Significance & R-square probablility & $\begin{array}{c}\text { Number of } \\
\text { comparisons } \\
\text { (significant) }\end{array}$ \\
H1 $a$ : horizontal & 91.32 & 0.26 & 0.74 & $25(0)$ \\
H1b: vertical & 33.44 & 0.38 & -- & -- \\
H1c (i): environmental values & 42.33 & 0.05 & 0.13 & $9(1)$ \\
H1c (ii): science attitudes & 20.96 & 0.19 & 0.48 & $9(0)$ \\
H1 $c$ (iii): scientist attitudes & 13.07 & 0.47 & 0.73 & $9(0)$ \\
H1 $c$ (iv): political ideology & 43.45 & 0.05 & 0.11 & $9(1)$ \\
H1 $c$ (v): barrier & 86.97 & 0.10 & 0.09 & $49(0)$ \\
H1 $d:$ expertise & 17.90 & 0.34 & 0.59 & $9(1)$ \\
& & & &
\end{tabular}

Note: Schneider et al. (2003) relate vertical position to levels of government, horizontal position to geographic jurisdiction, expertise position to scientific training, and ideological position to views underlying issue positions. Vertical, horizontal, and expertise codes were coded by researchers using definitions derived from these criteria. The worldview component draws from previously validated survey questions. These include scales developed to assess H1c (i) environmental values (Dunlap et al. 2000), H1c (ii) science attitudes, H1c (iii) the role of scientists in policy formation (Steel et al. 2004), H1c (iv) political ideology (General Social Survey 2006), and H1c (v) perceptions of dominant barriers to achieving the VRBP's objectives (Marshall et al. 2007).

unequal sample size. Conservatives are also more likely to tie to those with Liberal ideologies than to other Conservatives or than Liberals are likely to tie to each other.

A lack of ties among those who report scientific expertise and those who do not, and power asymmetries in this network, represent potential barriers to achieving the VRBP's mandate to develop science-based management options for the region. We were expecting more interaction between scientific "experts" and "nonexperts" within the VRBP, given the amount of media attention afforded to the science, and previous observations that scientific studies are used in very political ways (Bolin et al. 2008). The structure of the network also indicates that the structure of interactions is constrained by the inequitable distribution of power across views about the role of scientists in policy, that is, those believing scientists should make policy decisions have higher betweenness and degree centrality. Together, these results indicate that the VRBP may not be functioning to allow reciprocal interaction among "experts" and "nonexperts" necessary to achieve a space in which scientific information is transparent, shared, and deliberated. It also indicates that there may differences within the group as to what the role of science should be in policy making. 
Table 3. Network autocorrelation with variables with significant pairwise comparisons.

\begin{tabular}{|c|c|c|c|c|c|c|c|}
\hline & & \multicolumn{2}{|c|}{$\begin{array}{l}\text { Structural-block } \\
\text { model }\end{array}$} & \multirow[b]{2}{*}{ Greater/fewer ties $\dagger$} & \multicolumn{2}{|c|}{ Model fit } & \multirow[b]{2}{*}{ Probability } \\
\hline & & $\begin{array}{l}\text { Standard } \\
\text { coefficient }\end{array}$ & $\begin{array}{l}\text { Significa- } \\
\text { nce }\end{array}$ & & $\mathrm{N}$ & $\begin{array}{l}\text { Adjust- } \\
\text { ed R- } \\
\text { square }\end{array}$ & \\
\hline $\begin{array}{l}\text { H1c (i): } \\
\text { Environmental values }\end{array}$ & & & & & 2070 & 0.018 & 0.129 \\
\hline nonresponse to & nonresponse & 0.001 & 0.09 & + & & & \\
\hline nonresponse to & $\begin{array}{l}\text { dominant social } \\
\text { paradigm }\end{array}$ & -0.03 & 0.07 & + & & & \\
\hline nonresponse to & ecocentrist & -0.02 & 0.09 & + & & & \\
\hline $\begin{array}{l}\text { dominant social } \\
\text { paradigm to }\end{array}$ & nonresponse & 0.06 & 0.10 & - & & & \\
\hline $\begin{array}{l}\text { dominant social } \\
\text { paradigm to }\end{array}$ & $\begin{array}{l}\text { dominant social } \\
\text { paradigm }\end{array}$ & 0.04 & 0.31 & - & & & \\
\hline $\begin{array}{l}\text { dominant social } \\
\text { paradigm to }\end{array}$ & ecocentrist & 0.12 & 0.14 & - & & & \\
\hline ecocentrist to & nonresponse & -0.01 & 0.13 & + & & & \\
\hline ecocentrist to & $\begin{array}{l}\text { dominant social } \\
\text { paradigm }\end{array}$ & -0.09 & 0.02 & + & & & \\
\hline ecocentrist to & ecocentrist (intercept) & 0 & 0.10 & + & & & \\
\hline $\begin{array}{l}\text { H1c (iv): Political } \\
\text { ideology }\end{array}$ & & & & & 2070 & 0.019 & 0.111 \\
\hline nonresponse to & nonresponse & -0.04 & 0.26 & - & & & \\
\hline nonresponse to & Liberal & -0.04 & 0.28 & - & & & \\
\hline nonresponse to & Conservative & -0.04 & 0.21 & - & & & \\
\hline Liberal to & nonresponse & 0 & 0.43 & - & & & \\
\hline Liberal to & Liberal & 0.02 & 0.43 & + & & & \\
\hline Liberal to & Conservative & -0.02 & 0.32 & - & & & \\
\hline Conservative to & nonresponse & 0.04 & 0.14 & - & & & \\
\hline Conservative to & Liberal & 0.11 & 0.00 & + & & & \\
\hline Conservative to & $\begin{array}{l}\text { Conservative } \\
\text { (intercept) }\end{array}$ & 0 & 0.49 & + & & & \\
\hline
\end{tabular}




\begin{tabular}{|c|c|c|c|c|c|}
\hline H1d: Expertise & & & & & $2070 \quad 0.006$ \\
\hline nonresponse to & nonresponse & -0.08 & 0.09 & + & \\
\hline nonresponse to & nonscientist & -0.11 & 0.07 & + & \\
\hline nonresponse to & scientist & -0.07 & 0.09 & + & \\
\hline nonscientists to & nonresponse & -0.08 & 0.10 & + & \\
\hline non-scientists to & nonscientist & -0.03 & 0.31 & + & \\
\hline nonscientists to & scientist & -0.06 & 0.14 & + & \\
\hline scientist to & nonresponse & -0.03 & 0.13 & + & \\
\hline scientist to & nonscientist & -0.09 & 0.02 & - & \\
\hline scientist to & scientist (intercept) & 0.00 & 0.10 & - & \\
\hline
\end{tabular}

Note: Bold typeface denotes a significant relationship.

$\dagger$ Greater ties than expected $=(+)$; fewer ties than expected $=(-)$.

Although some research finds that conflict can sustain creativity, learning, and diversity in knowledge systems (Jehn et al. 1999), the policy literature generally suggests that minimizing conflict is best to reach mutually agreeable goals. From this perspective, the current shortcomings in the VRBP might be explained by its very short existence, and it is possible that, over time, the degree of conflict within the network might decline (e.g., Tilt et al. 2008). There are numerous examples of attempts at collaborative management that have taken longer, or failed altogether, because of different stakeholder perspectives about the proper role of science in policy making (see, for example, the politics of science that stalled progress in the Klamath River Basin in the Northwest U.S.; Brunner and Steelman 2005). Collaborations that have acknowledged the limits of scientific information as a source of indisputable facts, and that value local or native knowledge, have been more successful (Tilt et al. 2008). For instance, the Upper San Pedro Partnership found that a jointlearning effort in which participants share an understanding of the goals and the use of the science, and at the same time recognize that science will not guarantee resolution of conflicts, has been instrumental to their science-based approach (Saliba and Jacobs 2007).
The finding that ideological ties, that is, environmental and political orientation, vary within the network, is not surprising given the history underlying the founding of the VRBP and its relatively short and tumultuous tenure as a collaborative partnership. However, none of the studies previously mentioned have analyzed the structural relationship between powerful network positions and beliefs toward the role of science. Through this quantitative network analysis, we have been able to specifically identify where the power asymmetries in this partnership lie and what ideas or beliefs underlie that position. A structural approach allows for investigation of the barriers that come about because of the location of conflict within a group, rather than treating conflict as a binary and merely assessing its presence or absence within groups. The willingness of central actors, or brokers, to share views that disagree with their own perspective could be a large barrier to meeting the target outcomes of the VRBP. Central actors play a key role in fostering leadership, developing a shared knowledge, and motivating creativity in natural resource management (Bodin et al. 2006). They have access to, and can synthesize across, a large knowledge pool. On the other hand, if central members choose to exploit asymmetries in the network to advance their personal views, this can 
affect the group's ability to find common ground and define problems (Choo Wei 2007, Manring 2007). Research on social learning has shown that relying on these contexts is often perceived as a limitation to social learning because their inclusion does not lead to transformative change or present opportunities for creativity (e.g., Prell et al. 2008). The implication for the VRBP is that although the central actors' belief that scientists should serve as advocates in the policy process is consistent with the mission of the VRBP, it does not appear to be a view widely shared with the rest of the group. Not only could this view of science affect a number of the scientific and information-gathering functions of the partnership, such as how boundaries outside of the VRBP are spanned, whether the definition of research agenda is done or not done jointly, or if one methodological strategy is followed instead of testing a range of assumptions and hypotheses shared by nonexperts in the group (Manring 2007). The ideological differences between central and peripheral network actors might indicate deeper normative or epistemological differences of opinion among participants as to what role science should be playing in addressing water conflict in the regions. We have started to investigate this issue by further analyzing VRBP participants' beliefs about science and the role of science, and relating this to a qualitative analysis of how the conflict in the region is perceived and framed (Neff et al. 2008).

We acknowledge that the ultimate success of a watershed partnership, or any form of collaborative management, needs to be evaluated through longterm analysis of both its process and socialecological outcomes (Conley and Moote 2003, Muñoz-Erickson et al. 2007), as well as how well it meets stated policy goals. As such, the results presented here should not be interpreted as an evaluation of the success or failure of the VRBP but, rather, as an assessment of conditions that may promote or inhibit collaboration and their goals of science-based management. Given the short time span of the VRBP, we have observed that the partnership's information network and its ability to span multiple boundaries is conducive to collaboration, but that differences in structural positions between science "experts" and other members, as well as between central actors and the rest of the network, could inhibit collaboration and the success of the VRBP in the future. These barriers to more successful collaboration would not have come to light through any assessment of collaboration that either focused solely on individuals or the structure of the network.

\section{CONCLUSION}

Understanding the factors that promote collaboration in natural resource management is no simple task. The approach we have presented here provides a much different picture of the nature of conflict that permeates this Arizona watershed partnership. Neither the depictions in media sources that claim that there is not enough science, nor the perceptions of VRBP members who most commonly list values as the dominant barrier to VRBP success, adequately capture the complexity of water resource management in this case. Our research highlights the crucial role that perspectives about science and expertise can have in the way that information flows through the VRBP and, ultimately, what knowledge is produced and accepted by its stakeholders. This area has been greatly overlooked in the collaborative-management literature. In ongoing projects, we are using qualitative methods to further understand the role that science and expertise play in framing water-management issues in the region. We hope that our work stimulates even more attention from the collaboration and organizationalresearch community to examine the role of knowledge systems in the effectiveness of partnerships.

We consider the structural approach presented here, paired with perspectives and beliefs as attributes of the individuals in the network, valuable to the research and practice of collaborative natural resource management. Although the analyses used here are unlikely to provide prescriptive parameters for future watershed partnerships, using this method widely might provide insight into general characteristics that describe partnerships that are able to meet their stated objectives and those that are not. Understanding the structural relationships within partnerships can also help determine how groups can build adaptive capacity and resilience as a result of collaboration (Bodin et al. 2006, Janssen et al. 2006). Most importantly, we hope to have demonstrated the added value of incorporating belief attributes to analyze perceptual sources of conflict along with relational. As this case demonstrated, information sharing is not a useful proxy for understanding conflict without also taking into account the political and cultural context of the partnership. Future research should move beyond a solely structural or individual approach and toward a more integrated approach to identify barriers and opportunities to collaborative management. 
Responses to this article can be read online at: http://www.ecologyandsociety.org/voll5/iss3/art22/ responses/

\section{Acknowledgments:}

We are grateful to Bill Edwards of the Decision Center for a Desert City (DCDC), Arizona State University, for his help in conducting the survey for this research. We would also like to thank Timothy W. Collins and Arizona State Senator Tom O'Halleran for their valuable input in the early formulations of this research. This material is based on work supported by the National Science Foundation under Grant No. SES-0345945, Decision Center for a Desert City (DCDC) and Grant No. 0504248, National Science Foundation Integrated Graduate Education Research and Training (IGERT) in Urban Ecology. Any opinions, findings and conclusions expressed in this material are those of the author(s) and do not necessarily reflect the views of the National Science Foundation (NSF).

\section{LITERATURE CITED}

Armitage, D. 2005. Adaptive capacity and community-based natural resource management. Environmental Management 35:703-715.

Barks, C. 2007. Holt: Big Chino pipeline on track. Prescott Daily Courier. 14 February 2007. Prescott, Arizona, USA.

Berardo, R. 2009. Processing complexity in networks: a study of informal collaboration and its effect on organizational success. Policy Studies Journal 37(3):521-539.

Bodin, Ö., B. Crona, and H. Ernstson. 2006. Social networks in natural resource management: what is there to learn from a structural perspective? Ecology and Society 11(2): r2. [online] URL: http:/ /www.ecologyandsociety.org/vol11/iss2/resp2/.

Bolin, B., T. Collins, and K. Darby. 2008. Fate of the Verde: water, environmental conflict, and the politics of scale in Arizona's central highlands. Geoforum 39(3):1494-1511.
Borgatti, S., M. G. Everett, and L. C. Freeman. 2002. UCINET for windows: software for social network analysis. Analytic Technologies, Harvard, Massachussetts, USA.

Brass, D. J., and M. E. Burkhardt. 1993. Potential power and power use: an investigation of structure and behavior. Academy of Management Journal 36 (3):441-470.

Brass, D. J., J. Galaskiewicz, H. R. Greve, and W. P. Tsai. 2004. Taking stock of networks and organizations: a multilevel perspective. Academy of Management Journal 47(6):795-817.

Browning-Aiken, A., H. Richter, D. Goodrich, B. Strain, and R. Varady. 2004. Upper San Pedro Basin: fostering collaborative bi-national watershed management. Water Resource Development 20 (3):353-376.

Brunner, R. D., and T.D.Steelman, editors. 2005. Adaptive governance: integrating science, policy and decision making. Columbia University Press, New York, New York, USA.

Bulkeley, H. 2005. Reconfiguring environmental governance: towards a politics of scales and networks. Political Geography 24:875-902.

Cash, D. W., W. Adger, F. Berkes, P. Garden, L. Lebel, P. Olsson, L. Pritchard, and O. Young. 2006. Scale and cross-scale dynamics: governance and information in a multilevel world. Ecology and Society 11(2): 8. [online] URL: http://www.ecology andsociety.org/vol11/iss2/art8/.

Chan K., and J. Liebowitz. 2006. The synergy of social network analysis and knowledge mapping: a case study. International Journal of Management and Decision Making 7 (1):19-35.

Choo Wei, C. 2007. Information seeking in organizations: epistemic contexts and contests. Information Research 12(2):298. [online] URL:htt p://InformationR.net/ir/12-2/paper298.html.

Collins, T. W., and B. Bolin. 2007. Characterizing vulnerability to water scarcity: the case of a groundwater-dependent, rapidly urbanizing region. Environmental Hazards 7:399-418. 
Conley, A., and M. A. Moote. 2003. Evaluating collaborative natural resource management. Society and Natural Resources 16(5):371-386.

Cortner, H.J., and M.A. Moote. 1999. The politics of ecosystem management. Island Press, Washington, D.C., USA.

Costenbader, E., and T. W. Valente. 2003. The stability of centrality measures when networks are sampled. Social Networks 25:283-307.

Davy, D. 2006. Recipients: the key to information transfer. Knowledge Management Research and Practice 4: 17-25.

Dillman, D. A.. 2000. Mail and internet surveys: the tailored design method. Second edition. Wiley, New York, New York, USA.

Dunlap, R. E., K. D. Van Liere, A. G. Mertig, and R. E. Jones. 2000. Measuring endorsement of the new ecological paradigm: a revised NEP scale. Journal of Social Issues 56(3):425-442.

Galaskiewicz, J. 1985. Interorganizational relations. Annual Review of Sociology 11:281-304. Annual Reviews, Palo Alto, California, USA.

General Social Survey. 2006. GSS Questionnaires. National Data Program for the Sciences, University of Colorado, Denver, Colorado, USA. [online] URL:http://www.norc.org/GSS+Website/Publications/ GSS+Questionnaires/.

Gunther, A. C., and J. D. Storey. 2003. The influence of presumed influence. Journal of Communication 53(2):199-215.

Hanneman, R. A., and M. Riddle. 2005. Introduction to social network methods. University of California, Riverside, California, USA.

Hardy, C., N. Phillips, and T. B. Lawrence. 2003. Resources, knowledge and influence: the organizational effects of interorganizational collaboration. Journal of Management Studies 40 (2):321-347.

Henry, A. 2007. Ideology versus power as drivers of network cohesion: the case of regional planning. Maxwell Workshop on Organizations and the Natural Environment. 22-24 May, 2007. Syracuse, New York, USA.
Hirt, P., A. Gustafson, and K. L. Larson. 2008. The mirage in the valley of the sun. Environmental History 13:482-514.

Ibarra, H. 1993. Network centrality, power, and innovation involvement: determinants of technical and administrative roles. The Academy of Management Journal 36(3):471-501.

Janssen, M. A., Ö. Bodin, J. M. Anderies, T. Elmqvist, H. Ernstson, R. R. J. McAllister, P. Olsson, and P. Ryan. 2006. A network perspective on the resilience of social-ecological systems. Ecology and Society 11(1): 15. [online] URL: http: //www.ecologyandsociety.org/vol11/iss1/art15/.

Jasanoff, S. 1990. The fifth branch: science advisers as policy makers. Harvard University Press, Cambridge, Massachussets, USA.

Jehn, K. A., G. B. Northcraft, and M. A. Neale. 1999. Why differences make a difference: a field study of diversity, conflict, and performance in workgroups. Administrative Science Quarterly 44 (4):741.

Jenkins, M. 2006. The perpetual growth machine. High Country News. 12 June 2006. Paonia, Colorado, USA.

Knoke, D., and R. S. Burt. 1983. Prominence. Pages 195-222 in Burt, R. S., and M. J. Minor. Applied network analysis. Sage Publications, Beverly Hills, California, USA.

Koontz, T., T. A. Steelman, J. Carmin, K. S. Korfmacher, C. Moseley, and C. W. Thomas. 2004. Collaborative environmental management: what roles for government? Resources for the Future, Washington, D.C., USA.

Krackhardt, D. 1987. Cognitive social structures. Social Networks 9:109-134.

Krackhardt, D., and R. Stern. 1988. Information networks and organizational crises: an experimental simulation. Social Psychology Quarterly 51 (2):123-140.

Langenheim, V. E., E. DeWitt, and L. Wirt. 2005. Preliminary geophysical framework of the Upper and Middle Verde River Watershed, Yavapai County, Arizona. Open-File Report. U.S. Geological Survey, Reston, Virginia, USA. 2005-1154. 
Leach, W. D., and N. W. Pelkey. 2001. Making watershed partnerships work: a review of the empirical literature. Journal of Water Resources Planning and Management November/December 2001:378-385.

Lebel, L., P. Garden, and M. Imamura. 2005. The politics of scale, position, and place in the governance of water resources in the Mekong region. Ecology and Society 10(2): 18. [online] URL: http://www.ecologyandsociety.org/vol10/iss2/ $\underline{\operatorname{art} 18 / .}$.

Lubell, M., M. Schneider, J. T. Scholz, and M. Mete. 2002. Watershed partnerships and the emergence of collective action institutions. American Journal of Political Science 46(1):148163.

Manring, S. L. 2007. Creating and managing interorganizational learning networks to achieve sustainable ecosystem management. Organization and Environment 20(3):325-346.

Marsden, P. V. 1990. Network data and measurement. Annual Review of Sociology 16:435463.

Marshall, K., R. White, and A. Fischer. 2007. Conflicts between humans over wildlife management: on the diversity of stakeholder attitudes and implications for conflict management. Biodiversity and Conservation 16(11):3129-3146.

McGavock, E. 2003. Big Chino aquifers: knowns, unknowns, and conflicting interpretations. Tri-City Water Forum, Prescott, Arizona, USA.

Moreland, R., L., and A. R. Krishnan. 1996. Socially shared cognition at work: transactive memory and group performance. Pages 57-85 in J. Nye, and A. Brower, editors. What's social about social cognition. Sage Publications, Thousand Oaks, California, USA.

Muñoz-Erickson, T. A., B. Aguilar-González, and T. D. Sisk. 2007. Linking ecosystem health indicators and collaborative management: a systematic framework to evaluate ecological and social outcomes. Ecology and Society 12(2): 6. [online] URL: http://www.ecologyandsociety.org/vol12/ iss $2 / \operatorname{art} 6 /$.
Neff, M., B. Bolin, B. Cutts, K. Darby, L. Larson, T. A. Muñoz-Erickson, and A. Wutich. 2008. Does truth flow like water? The role of social networks in the flow of scientific understandings in a water management controversy. Association of American Geographers, Washington, D.C., USA.

Northern Arizona Land Exchange and Verde River Basin Partnership Act. 2005. Public Law 109-110. United States Statues at Large, 199 Stat. 2351-2362.

Olsson, P., C. Folke, and T. Hahn. 2004. Socialecological transformation for ecosystem management: the development of adaptive co-management of a wetland landscape in southern Sweden. Ecology and Society 9(4): 2. [online] URL: http://www.ecol ogyandsociety.org/vol9/iss4/art2.

Ostrom, E. 1990. Governing the commons: the evolution of institutions for collective action. Cambridge University Press, Cambridge, Massachussets, USA.

Pahl-Wostl, C., M. Craps, A. Dewulf, E. Mostert, D. Tabara, and T. Taillieu. 2007. Social learning and water resources management. Ecology and Society 12(2): 5. [online] URL: http://www.ecology andsociety.org/vol12/iss2/art5/.

Prell, C., K. Hubacek, C. Quinn, and M. Reed. 2008. "Who's in the network?" When stakeholders influence data analysis. Systemic Practice and Action Research 21(6): 443-458

Provan, K. G., A. Fish, and J. Sydow. 2007. Interorganizational networks at the network level: a review of the empirical literature on whole networks. Journal of Management 33(3):479-516.

Provan, K. G., and H. B. Milward, 1995. A preliminary theory of interorganizational network effectiveness: a comparative study of four community mental-health systems. Administrative Science Quarterly 40(1):1-33.

Reagans, R., and E. W. Zuckerman. 2001. Networks, diversity, and productivity: the social capital of corporate research and development teams. Organization Science 12:502-517 
Reisner, M. 1993. Cadillac desert: the American west and its disappearing water. Second edition. Penguin, New York, New York, USA.

Rowley, T. J. 1997. Moving beyond dyadic ties: a network theory of stakeholder influences. Academy of Management Review 22(4):887-910.

Rulke, D., and J. Galaskiewicz. 2000. Distribution of knowledge, group network structure, and group performance. Management Science 46(5):612-625.

Sabatier, P. A., W. Focht, M. Lubell, Z. Trachtenberg, A. Vedlitz, and M. Matlock. 2005. Collaborative approaches to watershed management. Pages 3-21 in P. A. Sabatier, W. Focht, M. Lubell, Z. Trachtenberg, A. Vedlitz, and M. Matlock, editors. Swimming upstream: collaborative approaches to watershed management. MIT Press, Cambridge, Massachusetts, USA.

Schneider, M., J. Scholz, M. Lubell, D. Mindruta, and M. Edwardsen. 2003. Building consensual institutions: networks and the national estuary program. American Journal of Political Science 47 (1):143-158.

Shutters, S. T., and B. B. Cutts. 2008. A simulation model of cultural consensus and persistent conflict. Pages 71-78 in V. S. Subrahamanian, and A. Kruglanski, editors. Proceedings of the Second International Conference on Computational Cultural Dynamics. AAAI Press, Menlo Park, California, USA.

SPSS Inc. 2001. SPSS Base 15.0 for Windows User's Guide. SPSS Inc., Chicago, Illinois, USA.

Steel, B., P. List, D. Lach, and B. Shindler. 2004. The role of scientists in the environmental policy process: a case study from the American West. Environmental Science and Policy. 7:1-13.

Tilt, W., C. Conley, M. James, J. C. Lynn, T. A. Muñoz-Erickson, and P. Warren. 2008. Creating successful collaborations in the West: lessons from the field. Pages 1-23 in C. Van Riper III, and M. Sogee, editors. The Colorado Plateau III: integrating research and resources management for effective conservation. University of Arizona Press, Tucson, Arizona, USA.

Wasserman, S., and K. Faust. 1994. Social network analysis: methods and applications.
Cambridge University Press, Cambridge, Massachussetts, USA.

Wegner, D. M. 1987. Transactive memory: a contemporary analysis of the group mind. Pages 185-208 in B. Mullen and G. R. Goethals, editors. Theories of group behavior. Springer, New York, New York, USA.

Wirt, L., E. DeWitt, and V. Langenheim. 2004. Geologic framework of aquifer units and groundwater flowpaths, Verde River headwaters, North-Central Arizona. Open File Report 20041411. U.S. Geological Survey, Reston, Virginia, USA. [online] URL: http://pubs.usgs.gov/of/2004/1 $\underline{411 /}$.

Wondolleck, J. M., and S. L. Yaffee. 2000. Making collaboration work: lessons from innovation in natural resource management. Island Press, Washington, D.C., USA.

Worster, D. 1985. Rivers of empire: water, aridity, and the growth of the American west. Pantheon, New York, New York, USA. 
APPENDIX 1. Survey questions.

Q2. Which organizations or governmental entities interested in the Big Chino Water Project are you affiliated with?

Q4. Please check all roles that describe your participation in the proposed Big Chino Water Project: Activist, Business Owner, Concerned Citizen, Consultant, Elected Official, Engineer, Outdoor Recreationalist, Policy Maker, Scientist, Water Manager, Other.

Q6. Please rate how well you agree with each of the statements below. Scale for the question: Strongly Disagree, Slightly Disagree, Neutral, Slightly Agree, Strongly Agree.

\section{Statements:}

A. Use of the scientific method is the only certain way to determine what is true or false about the world.

B. The advance of knowledge is a linear process driven by key experiments.

C. Science provides objective knowledge about the world.

D. It is possible to eliminate values and value judgments from the interpretation of scientific data.

E. Facts describe true states of affairs about the worlds.

F. Scientists should only report scientific results and leave others to make natural resource management decisions.

G. Scientists should report scientific results and then interpret the results for others involved in natural resource decision making.

H. Scientists should work closely with managers and others to integrate scientific results in natural resource decision making.

I. Scientists should be responsible for making decisions about natural resource management

Q9. Please rate how well you agree with each of the statements below. Scale for the question: Strongly Disagree, Slightly Disagree, Neutral, Slightly Agree, Strongly Agree.

Statements:

A. We are approaching the limit to the number of people the earth can support.

B. Humans have the right to modify the natural environment to suit their needs.

C. Humans have the right to modify the natural environment to suit their needs.

D. When humans interfere with nature it often produces disastrous consequences.

E. Human ingenuity will ensure that we do NOT make the earth unlivable.

F. Humans are severely abusing the environment.

$\mathrm{G}$. The earth has plenty of natural resources if we just learn how to develop them.

H. Plants and animals have as much right as humans to exist.

I.The balance of nature is strong enough to cope with the impacts of modern industrial nations.

J. Despite our special abilities humans are still subject to the laws of nature.

$\mathrm{K}$. The so-called "ecological crisis" facing humankind has generally been greatly exaggerated.

L. The earth is like a spaceship with very limited room and resources.

$\mathrm{M}$. Humans were meant to rule over the rest of nature.

$\mathrm{N}$. The balance of nature is very delicate and easily upset.

O. Humans will eventually learn enough about how nature works to be able to control it.

P. If things continue on their present course, we will soon experience a major ecological catastrophe.

Q10. How frequently do you interact with each of the following people concerning the Big Chino Water Project? Interaction can occur through face to face contact, presentations, meetings, through mail, email, telephone, fax, or websites (when the author can be identified). Please include interactions already described above, as well. [Names not included for confidentiality purposes].

Q12. We hear a lot of talk these days about Liberals and Conservatives. I'm going to show you a seven-point scale on which the political views that people might hold are arranged from extremely Liberal--point 1--to extremely Conservative-- point 7 . Where would you place yourself on this scale? 